\title{
Evaluation of a Teaching Sequence Regarding Science, Technology and Society Values in Higher Education
}

\author{
María Amparo Oliveros ${ }^{1}$, Alejandra García ${ }^{2}$, Benjamín Valdez ${ }^{2}$ \\ ${ }^{1}$ Manufacturing Engineering, Polytechnic University of Baja California, Mexicali, México \\ ${ }^{2}$ Institute of Engineering, Autonomous University of Baja California, Mexicali, México \\ Email:amparo@uabc.edu.mx, maoliverosr@upbc.edu.mx
}

Received 13 August 2015; accepted 13 September 2015; published 16 September 2015

Copyright ( 2015 by authors and Scientific Research Publishing Inc.

This work is licensed under the Creative Commons Attribution International License (CC BY). http://creativecommons.org/licenses/by/4.0/

(c) (i) Open Access

\section{Abstract}

This work shows the results of a teaching-learning sequence applied to the concept of the nature of science and technology implemented on manufacturing technology engineering students at Autonomous University of Baja California, Mexico, during the academic period 2012-2013. The sequence was implemented to the course of Applied Human Values, on which students ponder and debate on principles of science and technology; taking as main objective to identity student beliefs on ethics, and values and assumptions of science. The Methodological design is quasi-experimental, pre-post-test without controlling group. The study allows identifying a slight improvement in the engineering student beliefs about the aspects of science, technology and society that are being evaluated.

\section{Keywords}

Engineering Students, Instructional Sequence, STS Aspects, Values

\section{Introduction}

In a contemporary society that has been considerably affected by many social, political and economic transformations, the fading of borders due to globalization has caused a technology sophistication and knowledge complexity (Hargreaves, 2003; Lyotard, 1995). Therefore, when considering higher education institutions (HEIs) as shaping entities and sources of knowledge and culture, they have inherited the role of collaborating to a sustainable development of societies. Given these challenges, HEIs are seen as builders and transmitters of a new cultural project; on which innovation, production of new knowledge and learning of Science and Technology shall 
be encouraged (ANUIES, 2006; Leydesdorff \& Etzkowitz, 2001). In this context, there is a global discussion about a third industrial revolution, where extensive development of new technologies is evident, as well as scientific and technical advances that have led to increased generation of knowledge, which are favored as drivers of development and construction of a knowledge society (United Nations Educational, Scientific and Cultural Organization (UNESCO), 2005), where these societies must share their knowledge so that their development is in line with human beings and life, along the ever evolving technological developments (Orozco, 2009). From this perspective, knowledge development and transfer, impact both countries as well as higher education systems. This situation has led educational institutions to face new challenges, since their role is critical in creating new intellectual infrastructure that will be responsible for production, use and application of knowledge (World Bank, as quoted in Godinas, 2001).

For all the above, it is necessary to lay the ethical foundations in evolving knowledge societies; which should consider responsibility and freedom, as well as the shared use of knowledge (Crede \& Masell, 1998). In this sense, the professional and ethical responsibilities that HEIs promote in their students, constitute the social capital needed to build more prosperous civil societies joined together from a social perspective (UNESCO, 1998). Thus it is considered that to promote social responsibility, curricula should strengthen humanistic approaches and encourage students' values such as social commitment and interest to contribute in solving the most pressing problems of mankind (De Allende Diaz \& Garcia, 1998; UNESCO, 1998).

\section{The New Challenges of Engineering Education in Mexico}

Given the important role of science in the development of society, proposing a definition for the Nature of Science (NoS) is complex (Acevedo, 2008). To Lederman (1992) the NoS is understood as the values and assumptions inherent in the development of science and scientific knowledge, while McComas (2002) refers to the NoS as an integration of philosophy, sociology, psychology, history and epistemology of science. However, in this work, we considered the integrative approach of Nature of Science and Technology (NoS\&T), where we include: the definition of S\&T (Science and Technology), knowledge of science and technology, its internal and external functions, methods used to build, develop, validate and transfer the knowledge they produce, the values involved in scientific and technological activities, the characteristics of the scientific and engineering community, the links between science and technology, relations between society and the techno-scientific system and vice versa, as well as its contributions to culture and progress of society (Vázquez \& Manassero, 2012). In recent years, major technological changes have led to both the engineering practice as well as its teaching processes in the various institutions to go through several transformations in order to meet the workforce needs of different regions in search of a positive contribution to economic development. The National Academy of Engineering (NAE, 2004) recognizes that the result of the practice of engineering is technological innovation, therefore through engineering, certain needs can become new opportunities to generate goods that enable new ways of communication, improvements in production processes, and generally translate into improvements to the quality of life of society.

In countries like Mexico, these developments are constrained by social, political, in some cases religious, and very significantly, by economic factors. Despite the achievements in recent years in programs of organizations such as the National Council of Science and Technology (CONACYT), Mexico is set at the last positions among the countries of the Organization for Economic Cooperation and Development (OECD) due to indicators such as number of researchers, use of Technology Information and Communication in medium and small sized companies, number of patents per year, applied innovation, knowledge application via technological development, and scientific research investments (ANUIES, 2006).

While technological innovations have shown great benefits for the different disciplines that use them, the excessive use of energy sources or polluting materials in different economic sectors have also led to globally significant environmental impact which have caused drastic climate changes in some geographic areas. Therefore, future generations will require deep ethical awareness regarding the environment, a deep commitment to the creation of more efficient devices that consume less energy and have less emissions and using new energy sources (NAE, 2005). In this sense, the NAE (2014) suggests the need for utilization of high technology and new knowledge in the search for new materials increasingly resistant to environmental impacts or phenomena such as earthquakes, cyclones and floods.

Another problem that the NAE (2009) foresees in the near future and that will impact on the work of engineers, is the growth and aging of the general population. This poses some challenges that need to be addressed 
such as increased demand for medical services, new options to continue studying and staying active, scarcity and water quality, etc. For engineering this translates into the need to continue to develop devices for control and monitoring of new diseases or improve the quality of life of patients, best design for water treatment devices that enable reuse as far as possible, designing net-zero Buildings, continuing education offers at schools, among others.

Those countries that are able to respond to these new trends and needs will remain competitive globally. These new developments will mean more progress options for the more advanced countries but could lead to conflict for the least developed countries; therefore, technological innovation should be a subject present in the workshops of the educational authorities of these countries. Because of these trends, engineers who are ready to face this future will be required. Hence, they must be trained as individuals capable of working in multidisciplinary teams possess strong analytical, creative, innovation and ingenuity skills, to be aware of changes in their environment and global change, to have leadership skills, and be able to work in technical, business and public service areas, with a great ethical sense (NAE, 2005).

\section{Methodology}

The paper uses a pre-test post-test research design, without a control group, in order to find the students beliefs regarding science, technology and society values. The research was developed in three phases distributed as follows: in October 2012 the pre-test was applied to the experimental group, in the second stage in November, the teaching-learning sequence (TLS) was implemented (Oliveros et al. 2013); on which the relationship of science and religion were analyzed in a contemporary context through reading and conformation of work teams, allowing a debate of ideas between members of the participating groups, in order to promote critical thinking. The implementation of the TLS was very enriching, because it allowed the debate of ideas, and we were able to observe the students ability to integrate into teams, and the expression of critical thinking of the participants in the areas of science, technology and religion. The final stage corresponded to the implementation of the post-test in December 2012 using the assessment tool described below. The effectiveness of the intervention is assessed by comparing the initial and final scores obtained by the students in the questionnaire through attitudinal indices.

\subsection{Population and Sample}

The group on which the research was conducted, consisted of 30 students enrolled in the course of "Values of being" in a state public university in Mexicali, Baja California, Mexico that were taking the class for the first time and were randomly selected from groups in the humanities available. Group characteristics were the following: twenty male subjects representing 86.7 percent of the participants and four female representing 13 percent of participating students. The average age of the group is 21.4 years. By gender the age is distributed at an average 21.7 years for men and 19.2 years for women.

\subsection{Teaching Sequence}

The Teaching Learning Sequence used, "Science and Religion: reconcilable differences" is aimed to bring together the concepts of science, technology and society to students of the course "Values of being" that is offered to new majoring in Manufacturing Technology Engineering within the human development program. This resource poses current conflicts between scientists and religious people and presents arguments regarding the synergy that may exist between science and religion to invite the students to reflect on pros and cons of this issue. The structure of the TLS corresponds to an essay issued by the University of Berkeley, California, United States of America.

\subsection{Instrument}

The assessment tool was applied to measure the effectiveness of educational intervention on improving the understanding of students on NoS\&T. The evaluation was conducted through a paper questionnaire, which was completed by the students. In this paper, we outline the results obtained in the experimental group for one of the three questions that conforming the questionnaire, shown in Table 1 . The design of the evaluation tool considers the structure of the Questionnaire of Opinions on Science, Technology and Society (COCTS) which incorporates the issues from NoS\&T (Aikenhead \& Ryan, 1992) and uses the model of multiple choice and standardized indexes (Bennàssar et al., 2010;. Vázquez, Manassero, \& Acevedo, 2004). The three issues COCTS were selected based on their involvement in the topics addressed in the study. 
Table 1. Items discussed in the experimental group pre-test and post-test.

\begin{tabular}{|c|c|c|}
\hline Key & Dimensions & Scored statement \\
\hline 20411 & Ethics & $\begin{array}{l}\text { Some cultures have a particular point of view about nature and human beings. Scientists and } \\
\text { scientific research are affected by religious or ethical beliefs from the culture on which the } \\
\text { research is being made. }\end{array}$ \\
\hline 60311 & Beliefs & $\begin{array}{l}\text { A scientist's religious beliefs do not make a difference on the scientific discoveries he } \\
\text { makes. }\end{array}$ \\
\hline 90921 & Science assumptions & $\begin{array}{l}\text { Science rests under the assumption that the natural world cannot be altered by a higher } \\
\text { power (e. R. a god). }\end{array}$ \\
\hline
\end{tabular}

Students have to answer the question evaluating it based on a previously established scale of nine points (Vázquez \& Manassero, 1999). This score becomes an attitudinal index normalized according to the category of each sentence previously identified and assigned by a panel of expert judges. According to (Manassero \& Vázquez, 2001) these questions may be: adequate, if the sentence expresses an adequate and consistent opinion; plausible, if the statement is not entirely adequate or contains an aspect that is suitable, and naive, if the proposed sentence expresses aspects that are neither adequate nor plausible.

For indexes obtained, a value that is positive and near the maximum scale $(+1)$ represents a more informed and appropriate attitude. At the other extreme, a value that is more negative and close to $(-1)$ is interpreted as a more uninformed and naive attitude towards the question evaluated.

The questionnaire has a format that presents the theme of each issue and contains several statements regarding the different positions on the dimensions: assumptions about science, ethics and beliefs. Raw scores for the statements were assigned according to the following scale: 1, 2, and 3 for the level of disagreement; 4 for undecided; and 5, 6, 7, 8 and 9 for the level of agreement. Issues valued by students for the dimensions are as follows:

- Ethics, with statements regarding the influence of religious and ethical beliefs in scientific research.

- Beliefs, with statements regarding the influence of religious beliefs on scientific research.

- Assumptions of science, with statements regarding assumptions of scientific research in relation to the existence of a higher power.

\section{Results}

The aim of this study is to evaluate the improved understanding of the conception of the nature of science and technology in students, comparing the variation in scores of variables obtained by the evaluation instrument applied and described in the previous section. The overall analysis of the attitudinal indexes allows us to visualize if the beliefs and attitudes of the students changed after the completion of experiential workshop and the implementation of the TLS.

The standardized attitudinal indexes obtained in the evaluation indicate that there are uninformed beliefs regarding statements 20411 (Ethics) and 90921 (Assumptions of Science), observing the negative values found in the pre-test. However, the question 60311 representing scientists Beliefs scientists presented positive scores in the pre-test, which indicates that prior to application of the sequence, students had more informed beliefs.

The results of the pre-post-test regarding the issues considered in the study are shown in Figure 1.

Analyzing the attitudinal indexes by category for the issues 20411 (Ethics), 90921 (Assumptions of Science) and 60311 (scientists beliefs) may be seen in Table 2, global variations, where the biggest difference in the results of pre-test and post-test correspond to the appropriate category, and also the results show a setback in terms of appropriate student views. In terms of attitudinal indexes on "plausible" and "naive" categories, results indicate that there was a slight improvement in these beliefs. However, results were negative both in the pre -test and post-test in the case of "naive" category.

Raw scores on the pre-test and post-test, for each dimension, Ethics, Beliefs and Science Assumptions are shown in Figures 2-4.

Figure 2 shows that raw scores obtained by the students had a slight increase in the post-test in all statements of the Ethics dimension, except for the statement (20411E), which references the influences of political, religious or cultural groups to support or brake projects in a given subject, which belongs to the "plausible category". There was a minor variation of ratings in the statement (20411D) corresponding to the "plausible" category, addressing the influence of individual differences of scientists in the type of research undertaken. 


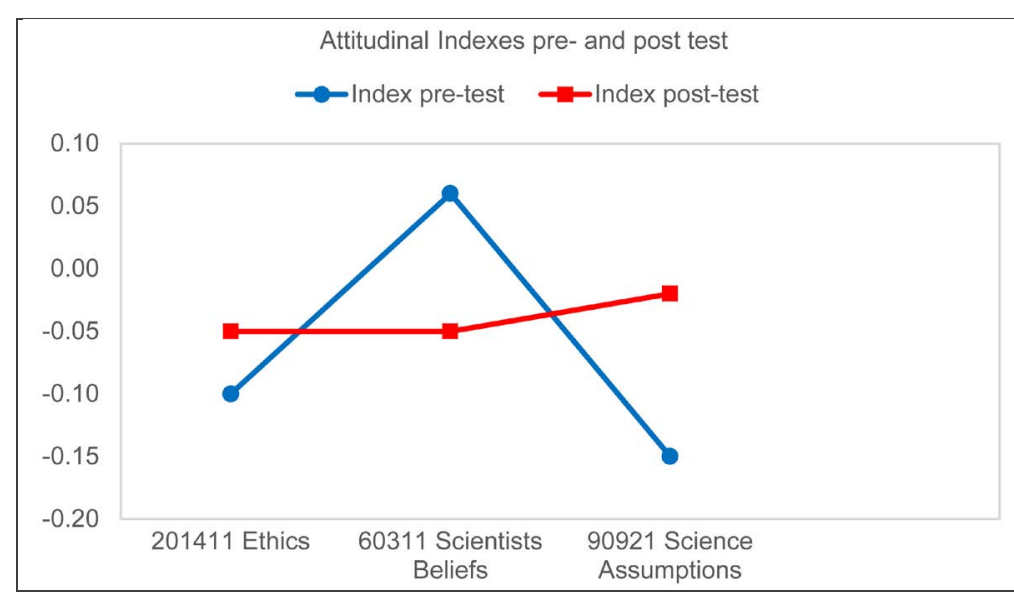

Figure 1. Attitudinal indexes pre-test and post-test by issue.

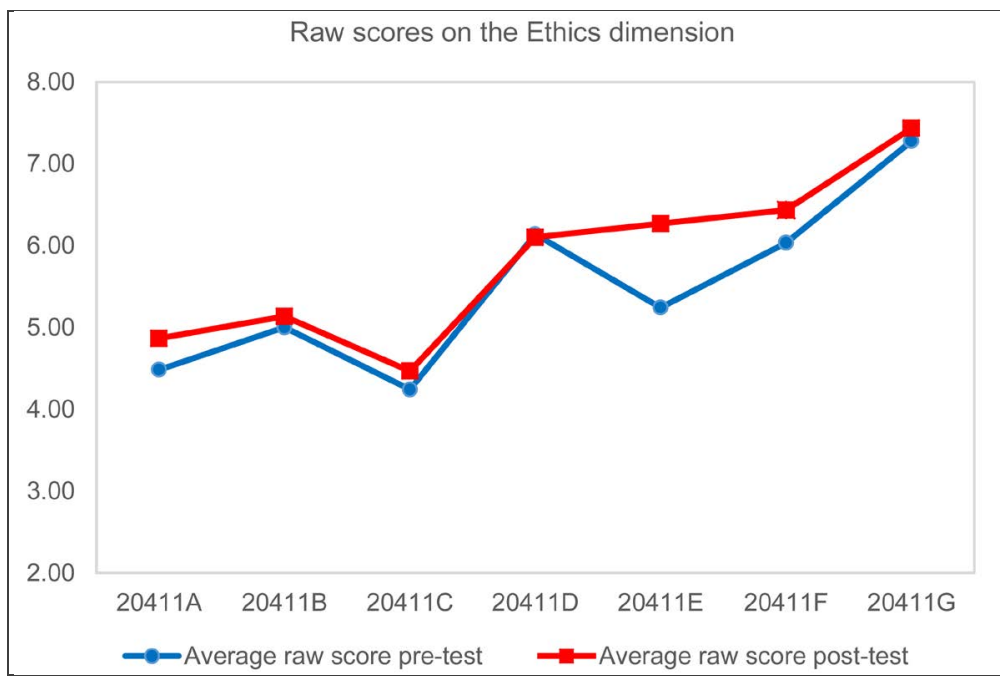

Figure 2. Raw scores on the pre-post-test for the ethics dimension.

Table 2. Attitudinal index by category.

\begin{tabular}{ccccc}
\hline Study & Pre-Test & Post-Test & Media & Typical Deviation \\
\hline Attitudinal index of “adequate" category & 0.360 & 0.280 & 0.320 & 0.057 \\
Attitudinal index of "plausible” category & 0.080 & 0.110 & 0.095 & 0.021 \\
Attitudinal index of "naïve" category & -0.280 & -0.240 & -0.260 & 0.028 \\
\hline
\end{tabular}

Figure 3 shows the raw scores obtained by students in the issues of the Beliefs dimension, presenting an increase in the raw value with a response of the "naive" category (60311A), where it is argued that religious beliefs do not produce differences about scientific discoveries. The results show a decrease in the "plausible" response (60311B) which states involvement in scientific discovery, only if that person favors their religious beliefs over their work. Similarly it is shown a decrease in raw scores in the appropriate statement (60311D); which states that beliefs sometimes affect the selection of the subject to work on.

Figure 4 shows that raw scores obtained by students declined in three issues or the Science Assumptions dimension, and only the "plausible" response (90921B), which states that the natural world cannot be altered by a higher power, had a very small increase in the raw scores assigned by students. Notably, there is a large decline in the statement (902921A) corresponding to the "plausible" category, where it is stated that the supernatural aspects go beyond scientific findings. 


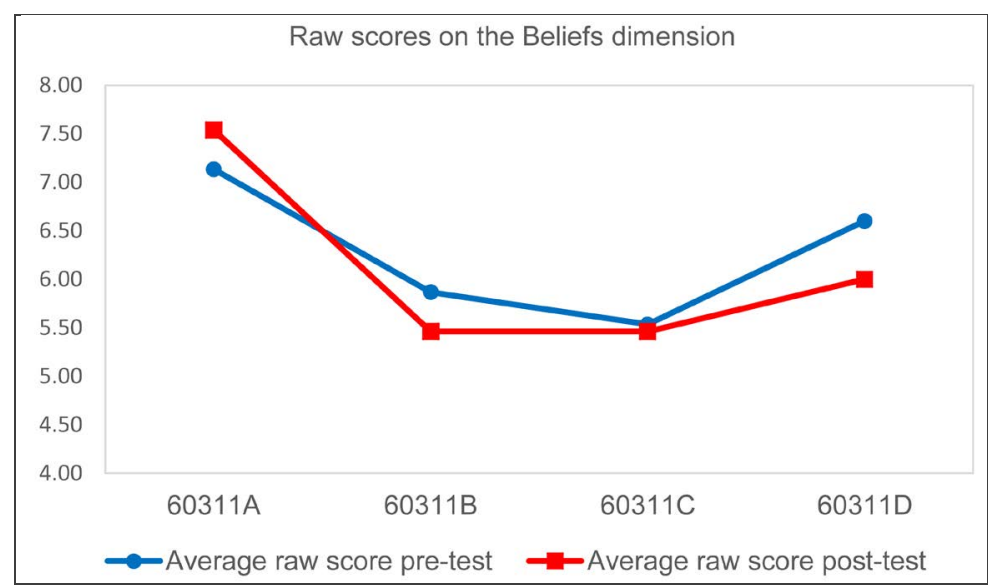

Figure 3. Raw scores on the pre-test, post-test for the beliefs dimension.

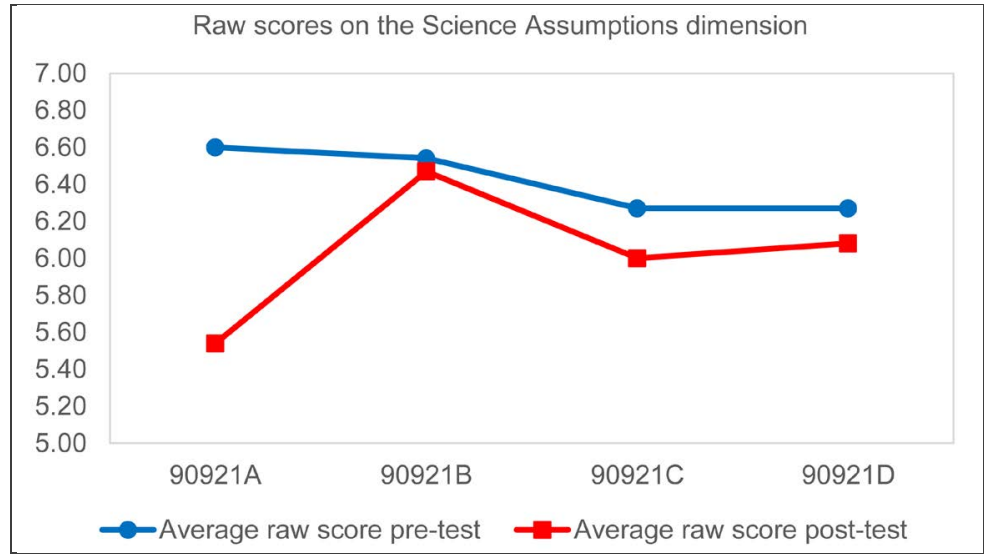

Figure 4. Raw scores on the pre-post-test for the science assumptions dimension.

\section{Conclusion}

The assessment of attitudes and beliefs relating to Science, Technology and Society (STS) represents a valuable contribution to the teaching of science. NoS\&T understanding, regarding the three issues assessed before and after application of the TLS can be measured based on the results for average global attitudinal indexes where we may conclude that the application of the TLS produced a slight improvement in perceptions of students who took part in the study group, as to the issues of external sociology of science ethics and the nature of scientific knowledge on the issue of Science Assumptions. However, the results suggest the need for strategies to help improve students' beliefs regarding the Internal Sociology of Science, in the Beliefs dimension.

In particular, the success of the proposal is linked to developments in the questions (20411E) belonging to the "plausible" category and the decrease in the "naive" statements (90921C) and (90921D), as raw scores show.

As for the difference between the pre-test and post-test, a slight variation in the rest of the responses for the different issues was observed. The above reflects the need to review the structure of the TLS, depending on the results, considering opportunities for improvement on dimensions in which there was not any progress of even to boost those who showed only a slight increase.

The study provides feedback to the teaching process on the Values of Being course, while providing a reference on students' beliefs regarding the NoS\&T to be considered in other courses within the area of Human Development Program on Manufacturing Technology Engineering.

The overall analysis of the results obtained before and after application of the TLS, identifies improvement opportunities on NoS\&T learning on the group of students tested. The particular analysis of results of the various issues of the TLS, show the need to adapt the content so that they may reinforce an adequate view on certain aspects of NoS\&T in students regarding the following specific issues: dimension (20411E) which refers to the 
influence of political, religious or cultural groups to support or brake projects in a given subject, which belongs to the "plausible "category", on the Ethics dimension.

For the Beliefs dimension, it is important to define strategies to improve student attitudes regarding statements (60311B), (60311C) and (60311D) related to the scientists 'religious beliefs and discoveries, belonging to categories "appropriate" and "plausible".

Regarding Science Assumptions, we found the need to strengthen the TLS in order to improve students' beliefs regarding statements (90921A), (90921C) and (90921D) belonging to the "plausible" and "naive" categories about scientists' positions regarding alterations of the natural world by a higher power.

\section{References}

Acevedo, J. A. (2008). The Current State of the Nature of Science in Science Education. Eureka Magazine Teaching and Dissemination of Sciences, 5, 134-169.

Aikenhead, G. S., \& Alan, G. R. (1992). The Development of a New Instrument: “Views on Science-Technology-Society” (VOSTS). Science Education, 76, 477-491. http://dx.doi.org/10.1002/sce.3730760503

ANUIES (2006). Consolidation and Advancement of the Higher Education in Mexico. Crucial Topics on the Agenda. National Association of Universities of Higher Education, Universidad Autónoma de México.

Bennàssar, A., Vázquez, Á., Manassero, M., \& García, A. (2010). Science, Technology and Society in Latin America: An Assessment of the Understanding of the Nature of Science and Technology. OEI Center of University High Studies. http://www.oei.es/salactsi/DOCUMENTO5vf.pdf

Crede, A., \& Mansell, R. (1998). Knowledge Societies. In a Nutshell: Information Technologies for Sustainable Development. Ottawa: IDRC.

De Allende, D., \& Gallardo (1998). Higher Education in Mexico and in the Developing Countries from the Perspective of International Organizations. Mexico: Collection Documents ANUIES 16:378.

Godinas, L. (2001). Building Knowledge Societies: New Challenges for Higher Education. Executive Summary Extracted from the World Bank Report. Educational Profiles, 23, 98-113.

Hargreaves, D. (2003). Teachers, Culture and Postmodernism. Times Change, Change Teachers. Madrid: Editions MORATA, S.L.

Lederman, N. G. (1992). Students' and Teachers' Conceptions of the Science: A Review of the Research. Journal of Research in Science Teaching, 29, 331-359. http://dx.doi.org/10.1002/tea.3660290404

Leydesdorff, L., \& Etzkowitz, H. (2001). The Transformation of University-Industry-Government Relations. Electronic Journal of Sociology, 5, 338-344.

Lyotard, J. F. (1995). The Postmodern Condition. Mexico: Latin American Publishing Network.

Manassero, M. A., \& Vázquez, Á. (2001). Tools and Methods for Evaluating the Attitudes Related to Science, Technology and Society. Science Education, 20, 15-27.

McComas, W. (2002). The Role and Character of the Nature of Science in Science Education. Science \& Education, 7, 511532. http://dx.doi.org/10.1023/A:1008642510402

National Academy of Engineering (2004). The Engineer of 2020: Visions of Engineering in the New Century (pp. 54-60). Washington DC: National Academies Press.

National Academy of Engineering (2005). Educating the Engineer of 2020: Adapting Engineering Education to the New Century (pp. 60-72). Washington DC: National Academies Press.

National Academy of Engineering (2009). Ethics Education and Scientific and Engineering Research (pp. 84-93). Washington DC: National Academies Press.

National Academy of Engineering (2014). Importance of Engineering Talent to the Prosperity and Security of the Nation (pp. 35-42). Washington DC: National Academies Press.

National Council of Science and Technology. CONACYT. http://www.conacyt.mx/

Oliveros, M. A., Valdez, B., Vargas, L., \& Sevilla, J. (2013). Conception of Science, Technology and Society of Engineering Students from Two Institutions of Higher Education within Education Ministry Common Space. Iberoamerican Magazine for Research and Educational Development, 10, 1-7.

Organization for Economic Cooperation and Development. http://www.oecd.org/

Orozco, B. (2009). Competencies and Curriculum: A Tense and Complex Relationship. Proceedings of the X Mexican Congress of Educational Research, Veracruz. 
UNESCO (1998). World Declaration on Higher Education in the XXI Century. http://unesco.org

UNESCO (2005). Toward Knowledge Societies. Paris: UNESCO. http://unesdoc.unesco.org/images/0014/001419/141908s.pdf

Vázquez, Á., \& Manassero, M. (1999). Response and Scoring Models or the Views on Science-Technology-Society Instrument. International Journal of Science education, 21, 231-247. http://dx.doi.org/10.1080/095006999290679

Vázquez, Á., \& Manassero, M. (2012). The Selection of Content to Teach the Nature of Science and Technology. Part 1: A Review of the Contributions of Educational Research. Eureka Magazine on Teaching and Dissemination of Sciences, 9, 231.

Vázquez, Á., Acevedo, A., \& Manassero, M. (2004). Consensus about the Nature of Science: Evidence and Implications for Teaching. Iberoamerican Magazine. http://www.rieoei.org/deloslectores/702 